\title{
Pemberdayaan Masyarakat untuk Desa Persiapan pada Desa Batu Asaq melalui Pelatihan dan Pendampingan Berbasis Participatory Rural Appraisal
}

\author{
Zainudin Abdussamad', Abdul Muhid ${ }^{2}$, Syamsurrijal ${ }^{3}$, Sutarman ${ }^{4}$ \\ zainudinabdussamad@universitasbumigora.ac.id ${ }^{1}$, abdulmuhid@universitasbumigora.ac.id ${ }^{2}$, \\ syamsurrijal@universitasbumigora.ac.id ${ }^{3}$, sutarman@universitasbumigora.ac.id ${ }^{4}$ \\ 1,2,3,4Universitas Bumigora
}

Article History:

Received: 30-11-2021

Revised: 21-01-2022

Accepted:24-01-2022
Abstract: The community service which was done to the community in the Batu Asak village aims at helping the community to improve the skill in providing thelocal delicacies (jajanan Lokal) hygienically, attractive packing model, and marketing management. This village is a new village that requires many supports including human resources to establish a skilled community in the future. The service program was done for three months starting from September to November in 2021. to complete this program, the team passes some phases, namely; planning, coordinating, socializing, training, and mentoring. the method used is Participatory Rural Appraisal (PRA) the activity was done through training and mentoring to maintain the skill of the community in producing jajan Lokal hygienically. The result shows that the communities are able to provide the jajanan lokal hygienically, the products have been packed accompanied with the label. Hence, in the future, the team expects much support from University,

Keywords: Empowerment, Villagers, Training, Mentoring people and government, in order, the lecturers can do more collaboration

\section{Pendahuluan}

Perubahan pola hidup masyarakat pedesaan sudah mulai terlihat dari sisi kreatifitas masyarakat yang terus menerus bermunculan. Perubahan tersebut adalah salah satu konsekuensi logis perkembangan suatu wilayah dan ekspansi wilayah perkotaan kewilayah lahan produktif dekat perdesaan. Otomatisasi perubahan pola pikir dan pola hidup masyarakatpun tak terelakkan (Udin et al., 2016). Jika kita melihat lebih jauh tentang perubahan yang terjadi maka akan terlihat dua faktor penyebab; pertama faktor eksternal yaitu kebijakan pemerintah yang memberikan ijin terhadap perluasan wilayah, atau terjadinya pemekaran suatu wilayah baik desa maupun kota. Disamping pengaruh perluasan wilayah perkotaan yang harus menggeser wilayah pedesaan, ada faktor internal juga yang sangat berpengaruh signifikan terhadap perubahan diri seorang atau masyarakat tersebut,

yaitu adanya desakan dalam diri manusia itu yang harus menaggapai perubahan tersebut dengan gaya yang berbeda-beda (Baiquni, 2007). 
Desa Batu Asaq merupakan desa persiapan yang pisah dari desa induk Desa Batujai. Sebagai desa persiapan yang siap secara administratif tentu persiapan tidak hanya sampai disitu akan tetapi mengharuskan Sumber Daya Manusia (SDM) didalamnya harus berbenah diri. Berpisahnya desa Batu Asak dari desa induk berdampak pada seluruh aspek penghidupan masyarakat. Sehingga, masyarakatnya pun harus memiliki visi yang setidaknya sama untuk memajukan desa Batu Asaq. Cikal bakal desa baru ini sudah mulai menunjukkan kesiapan diri untuk benar-benar lepas dari desa induk, baik sosial maupun ekonominya. Dalam penelitian lain yang serupa pernah dilakukan oleh (Baiquni, 2007; Udin et al., 2016) mengatakan bahwa perubahan itu terjadi sebagai respon dari lingkungan sekitar.

Tujuan yang akan disampaikan dalam kajian ini adalah bagaimana masyarakat desa persiapan ini menyikapi isu perubahan kultur baru setelah berpisah dari desa induknya. Sehingga, dipandang perlu adanya pelatihan dan pendampingan yang mampu menyelaraskan antara karakter baru masyarakat desa Batu Asaq dengan pola hidup mereka. Hal ini sejalan dengan pemikiran (Zuraida, 1981) yang mengatakan bahwa masyarakat itu akan menggunakan peluang itu sesuai dengan seberapa besar akses kreatifitas yang mereka miliki agar dapat melakukan perbaikan penghidupan mereka agar pundi perekonomian dapat ditopang.

Penghidupan suatu kelompok masyarakat dapat berubah jika bersedia meninggalkan keterpurukan masa lalu mereka dan beralih ke masa yang akan membawa mereka kearah yang lebih baik dan salah satu cara yang dapat dilakukan adalah dengan cara pemberdayaan. Karena melalui pemberdayaan, kehidupan yang mandiri dapat terwujud (Sumodiningrat, 2000). Akan tetapi, masyarakat terlalu berpikir resiko tinggi ketika akan keluar dari zona nyaman, padahal keniscayaan akan perubahan sudah didepan mata. Sehingga kekuatan tim sangat dibutuhkan dalam mengubah mindset masyarakat. Tim pengabdi dari universitas harus terus bersinergi dengan masyarakat sehingga pola pikir dan kreatifitas masyarakat dapat diakomodir. Disisi lain, masyarakat juga harus ikut berperan aktif guna mempercepat pemberdayaan (Widjajanti, 2011). Dalam penelitian lain seperti yang ditulis oleh (Haris, 2014) mengatakan bahwa percepatan pemberdayaan dapat dilakukan dengan mudah ketika masyarakat memiliki keinginan untuk maju dan mau berubah.

\section{Metode}

Tim pengabdi dari universitas melakukan kegiatan pengabdian dalam rangka pemberdayaan masyarakat desa persiapan desa Batu Asaq dilakukan dengan menerapkan metode pelatihan dan pendampingan yang berbasis pada Participatory Rural Appraisal. Dimaksudkan agar masyarakat yang didampingi tetap fokus pada pelatihan dan https://journal.universitasbumigora.ac.id/index.php/ADMA

E-ISSN: 2723-7370 
membuahkan hasil yang maksimal. Disamping itu metode ini dapat membantu masyarakat dalam menganalisa dan memecahkan masalah yang dihadapi saat mengembangkan usahanya dikemudian hari. Metode ini sejalan dengan yang dikemukakan oleh (Gitosaputro, 2006) dalam penelitiannya tentang Implementasi Participatory Rural Appraisal (PRA) dalam Pemberdayaan Masyarakat. Dalam penelitiannya ini dia mengatakan bahwa metode ini merupakan suatu model pendekatan yang langsung bersentuhan dengan masyarakat. Sebelumnya, pendapat ini juga pernah dikemukakan oleh (Chambers, 1994).

Sasaran dalam pengabdian ini adalah para pelaku bisnis kecil yang dilakukan dirumah warga sendiri, di desa persiapan desa Batu Asaq hususnya di dusun Petak yang terdiri dari empat RT. Ada beberapa kelompok industri rumahan, yang memerlukan bantuan husus dalam pengembangan usaha mereka. Baik bantuan berupa manajerial, pengemasan hingga pada pemasaran.

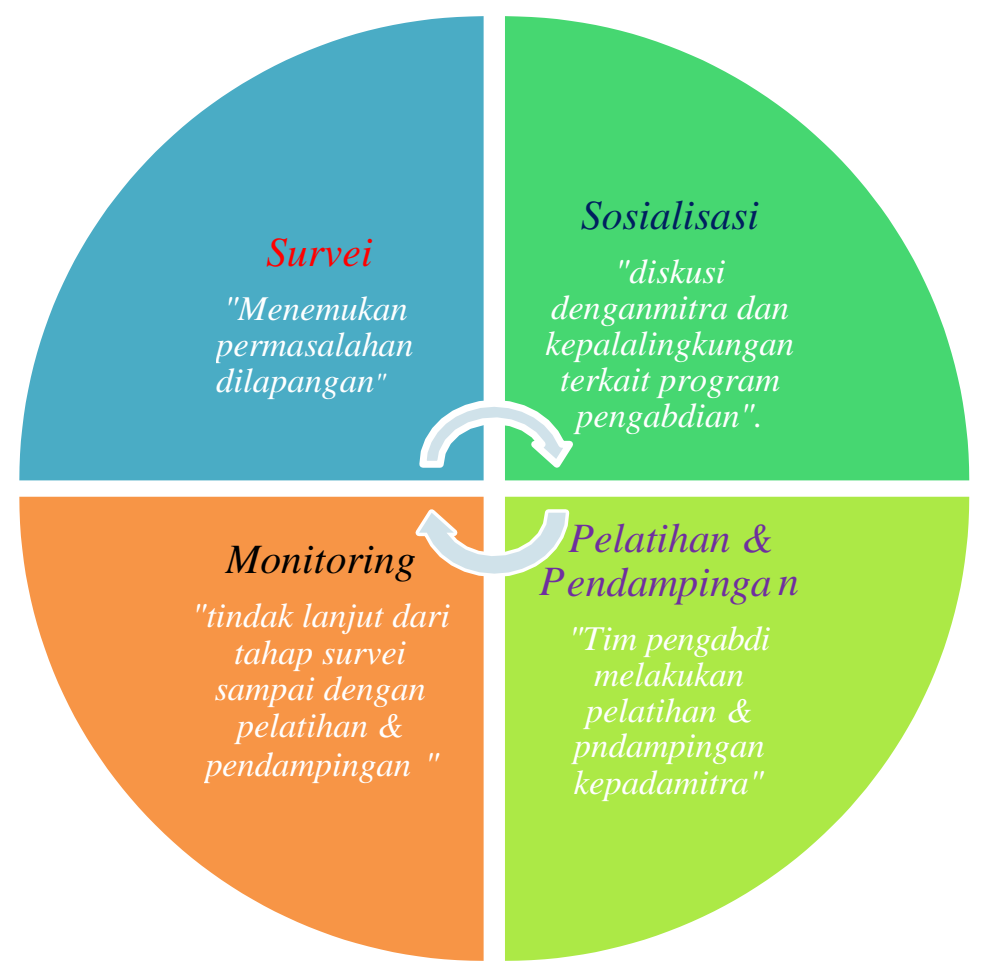

Gambar 1. Metode pengabdian

\section{Pembahasan}

Program pemberdayaan masyarakat bagi desa persiapan desa Batu Asaq dilakukan dengan berbagai tahapan yang rigid oleh tim pengabdi mendapat respon positif dari masyarakat maupun aparat dusun desa persiapan. Sebagai desa bentukan baru yang pisah dari desa induknya, tentu merupakan sebuah anugerah bagi masyarakat setempat karena mendapatkan program pemberdayaan masyarakat yang besinergi dengan kampus. Dengan https://journal.universitasbumigora.ac.id/index.php/ADMA 
program ini, masyarakat merasakan mafaat positifnya baik manfaat untuk usaha rumahan maupun secara individual. Berikut tim mendeskripsikan langkah-langkah dalam pemberdayaan:

\section{Perencanaan}

Mengawali kegiatan pengabdian ini, tim pengabdi membutuhkan perencanaan yang matang demi tercapainya hasil yang maksimal. Diawal pertemuan dengan beberapa anggota tim, kami membahas lokasi dan jenis kegiatan pengabdian yang akan dilakukan.

Dalam pertemuan tersebut diputuskan ada beberapa kelompok kegiatan masyarakat yang sudah mulai dirintis oleh masyarakat desa persiapan yang akan dijadikan objek pengabdian. Lokasi yang dijadikan sampel dalam pegabdian ini adalah Dusun Petak salah satu dusun yang berada diwilayah desa persiapan desa Batu Asak. SDM (Sumber Daya Manusia) Kampung ini cukup produktif dan inovatif, terutama dalam menghadapi era pandemi saat ini.

Pelatihan dan pendampingan yang diberikan kepada masyarakat tersebut adalah bagaimana agar mereka menghasilkan olahan yang higienis, memiliki kemasan yang menarik dan cepat laku dipasaran. Tidak hanya itu, tim pengabdi juga membantu mendampingi untuk pemasaran produk direkan sejawat di tempat kerja, sekaligus sebagai bentuk promosi.

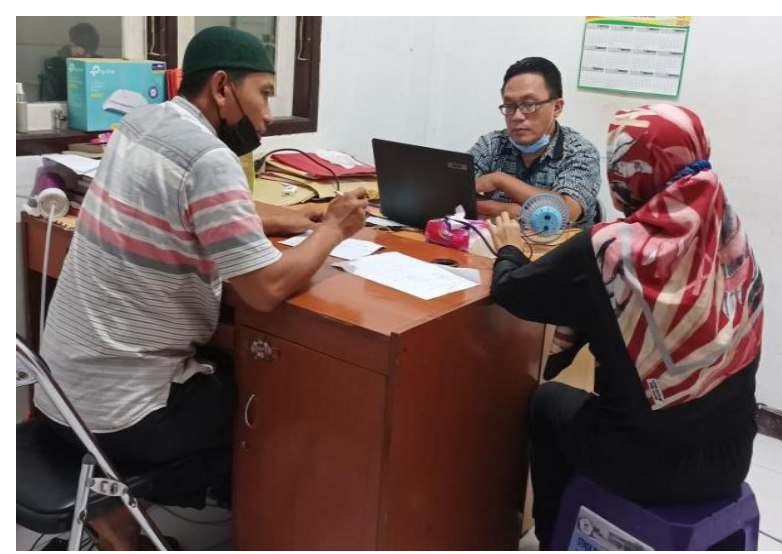

Gambar 2. Rapat perencanaan

\section{Koordinasi}

Tahapan berikutnya setelah perencanaan adalah tim berkoordinasi dengan kepala lingkungan, remaja dan beberapa anggota masyarakat desa persiapan dirumah kepala lingkungan dan di skeretariat PKBM selaku mitra. Dari pihak PKBM memfasilitasi tim dengan memberikan tempat pertemuan, peminjaman printer dan jilid laporan. 


\section{Arahan danSosialisasi}

Dalam pelaksanaan kegiatan pengabdian ini, tim sudah membagi tugas sesuai dengan kesepakatan bersama. Terkait kepakaran yang bersifat tehnis, tim melakukan kerjasama dengan pihak yang kompeten dibidangnya. Hal sederhana yang dilakukan tim adalah melakukan survey dan mensosialisasikan program pengabdian ini kepada mitra yang akan dijadikan bagian dari kerjasama. Ini merupakan edukasi dini yang diberikan kepada mitra agar dapat bekerjasama secara maksimal dengan tim selaku dosen pengabdi yang akan melaksanakan pengabdian. Hal serupa juga dilakukan oleh (Sukamta, 2017)dengan tema kajian menghadapi era digital.

Pengabdian ini menggunakan pendekatan pelatihan dan pendampingan yang berbasis PRA (Participatory Rural Apraisal). Pada kegiatan pelatihan, tim melakukan pelatihan kepada masyarakat desa persiapan desa Batu Asaq tentang proses pengolahan secara higienis, pembukuan, pengemasan hingga pada pemasaran hasil produksi. Pada tahapan ini, tim pengabdi menyisipkan ide-ide mendasar yang akan membantu pengembangan usaha mereka kedepan. Tanpa kendala besar, tim pengabdi berupaya menyesuaikan diri dengan masyarakat yang sedang berupaya bertransformasi ke salah satu jenis mata pencaharian baru selain pertanian dan tenun. Betapa tidak, karena masyarakat tersebut ingin keluar dari kungkungan belenggu satu model pencaharian dan mereka ingin ada suasana baru yang mampu menyokong perekonomian mereka sehingga asap dapur tetap mengepul. Kehidupan masyarakat NTB pada umumnya merasa sudah nyaman dengan bertani ternak, sehingga keluar dari zona nyaman ini mereka masih ragu. Akan tetapi masih ada sebagian masyarakat kita yang berupaya keluar dari cangkang dan menjelajah dunia baru dalam mata pencaharian mereka. Ini mungkin yang dimaksud dengan salah satu mekanisme bertahan hidup oleh (Dharmawan, 2007) dalam kajiannya yang berjudul SistemPenghidupan dan Nafkah pedesaan.

Kegiatan pelatihan ini dilanjutkan dengan kegiatan pendampingan warga dalam demo pengolahan bahan pangan secara higienis. Sehingga pada akhir kegiatan pengabdian masyarakat desa persiapan desa Batu Asaq mampu mengolah bahan secara higienis dan melakukan pengemasan barang dengan baik. Dibawah ini adalah beberapa dokumentasi sosialisasi kepada masyarakat dalam mengawali pengabdian. 


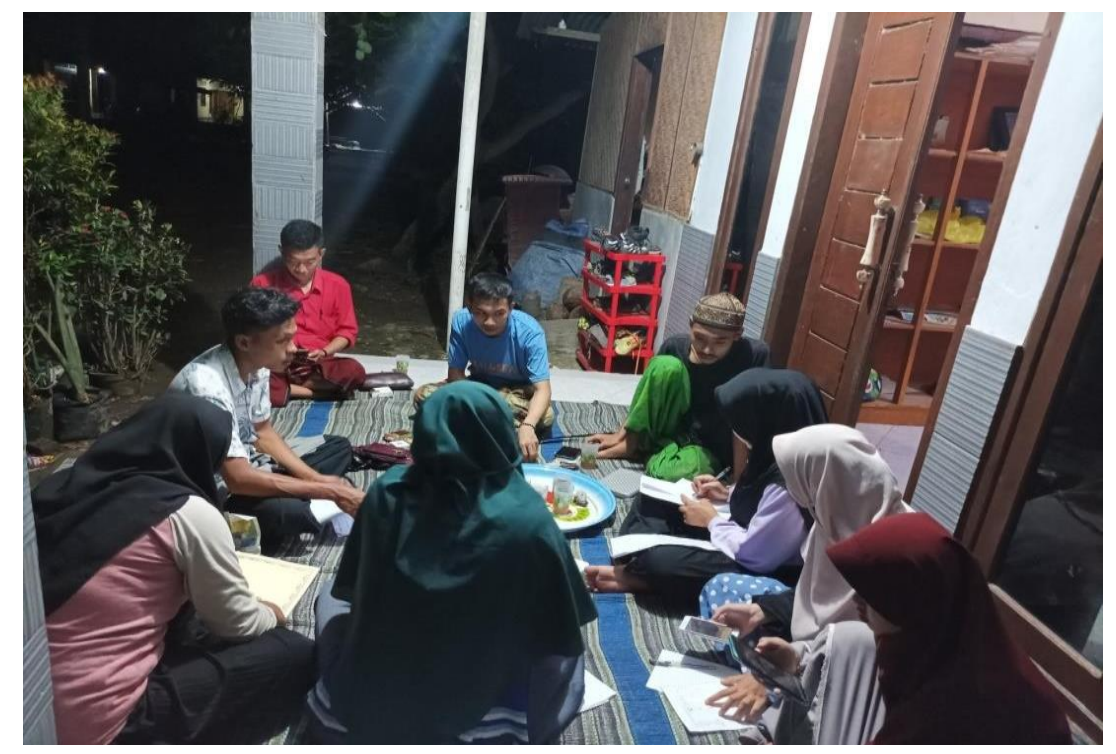

Gambar 3. Sosialiasasi kegiatan

\section{Fitrifool Crackers}

\section{Rengginang Mini Kare-kare Mini $\square$ Ore Mini}

J. H. Ihsan Dusun Petak Selatan IPDN Kampus NTB - 08175777160
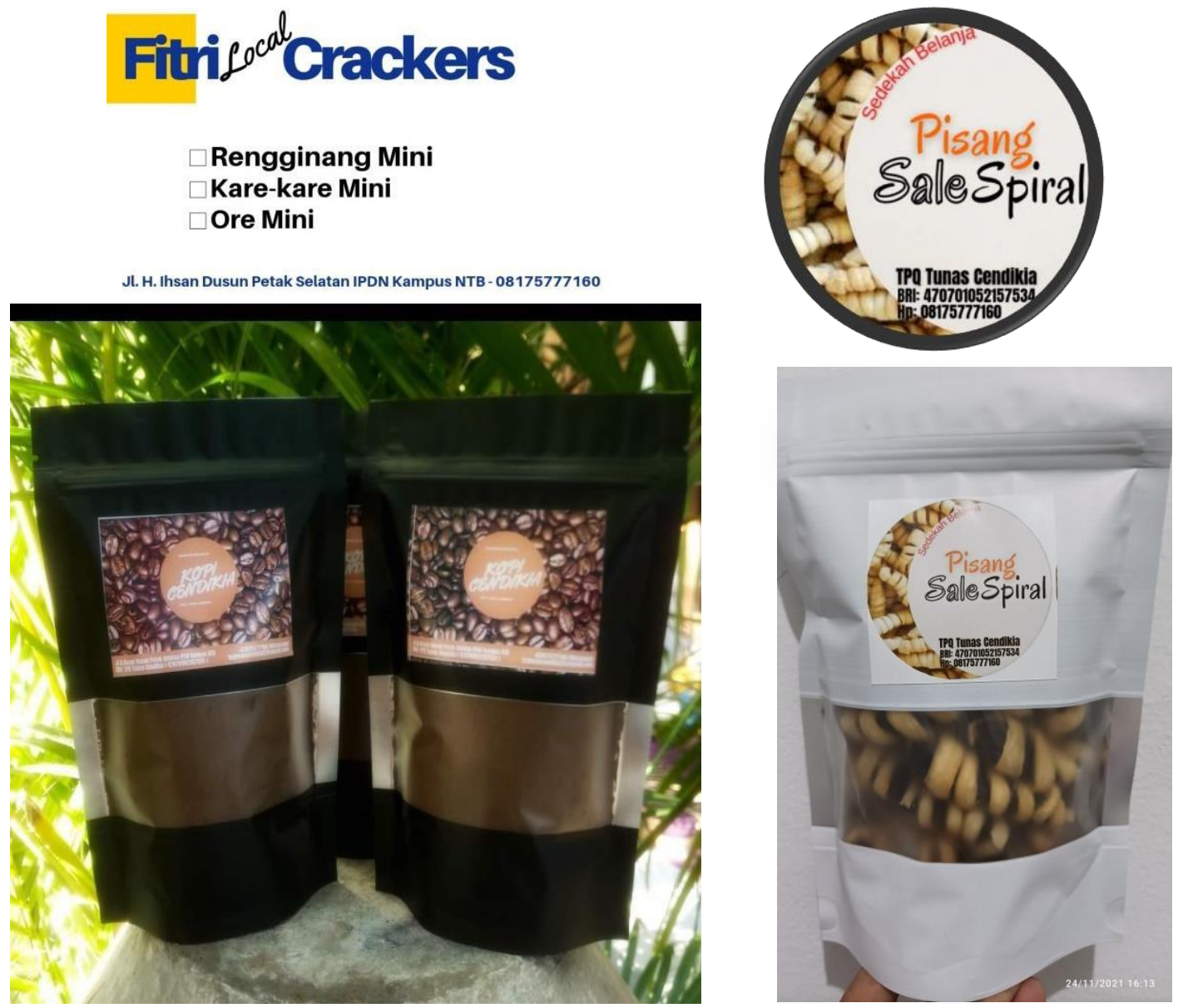

Gambar 4. Sticker \& kemasan

\section{Pelatihan}

Pelatihan yang diberikan bukan pelatihan cara membuat jajanan lokal tetapi lebih https://journal.universitasbumigora.ac.id/index.php/ADMA

E-ISSN: 2723-7370 
pada bagaimana menghasilkan produksi yang yang higienis memiliki daya saing dipasar baik dari segi higinitas maupun dari model kemasan, selain dari pelatihan yang diberikan oleh tim pengabdi diharapkan mampu meningkatkan produktifitas dengan waktu yang relatif singkat. Dan untuk mencapai target ini, tim pengabdi juga mengajak tim pakar yang membantu memberikan tambahan pengetahuan terkait dengan bidang produksi. Hal serupa juga dikemukakan oleh (Virgilenna \& Anom, 2018).

\section{Pendampingan \& Pemasaran}

Setelah beberapa langkah diatas sudah selesai dilakukan maka tanggungjawab lain yang diberikan oleh tim pengabdi kepada mitra yaitu membantu memasarkan hasil produksi secara online maupun ofline (Maryani et al., 2018; Melati et al., 2020; Oktaviani \& Rustandi, 2018). Pemasaran yang dilakukan saat ini masih pada lingkungan kerja. Maksud lain dengan pemasaran terhadap teman adalah agar lebih mudah meminta pendapat terhadap hasil produksi. Diharapkan akan ada testimony dari mereka terhadap produk yang kami pasarkan. Pelatihan dan pendampingan kepada beberapa kelompok ibu-ibu rumah tangga dan remaja.
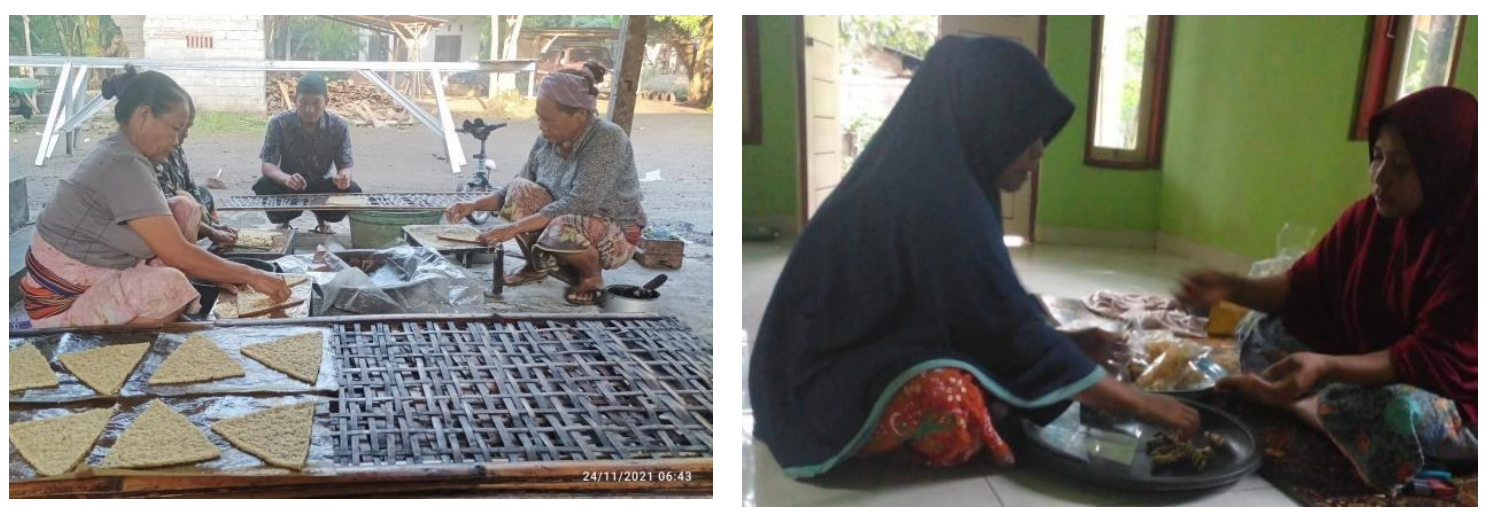

Gambar 5. Kegiatan pendampingan \& pengemasan

\section{Kesimpulan}

Pelatihan dan pendampingan oleh tim pengabdi dari Universitas merupakan salah satu bentuk tridarma yang harus dilakukan oleh Dosen. Kegiatan pengabdian ini merupakan kegiatan rutin dosen yang harus terpenuhi setiap semester. Dari pelatihan yang dilakukan selama tiga bulan ini, masyarakat persiapan sudah mampu menunjukkan hasil yang cukup signifikan yaitu dalam proses pembuatan jajanan lokal, mereka memperhatikan kebersihan meskipun masih bersifat tradisional. Selain itu, sekarang masyarakat sudah memiliki merek produk dan model kemasan yang dapat menarik perhatian calon pembeli.

Harapan kedepan, pengabdian yang berbasis produk dan keterampilan perlu ditingkatkan sehingga hasil pengabdian benar-benar riil dapat dirasakan manfaatnya oleh https://journal.universitasbumigora.ac.id/index.php/ADMA

E-ISSN: 2723-7370 
masyarakat. Selain itu, pemerintah atau lembaga asal pengabdi perlu memperhatikan jumlah pendanaan demi kelancaran proses pelatihan danpengabdian.

\section{Ucapan Terimakasih}

Tim pengabdi mengucapkan banyak terimakasih kepada Universitas Bumigora yang sudah mendukung tim dalam melaksanakan pengabdian baik dari ijin maupun pendanaan yang cukup membantu tim dalam menuntaskan tugas dilapangan. Tidak lupa tim mengucapkan terimakasih yang sebesar-besarnya kepada kepala lingkungan dusun Petak yang memberikan ijin mengabdi memberikan pelatihan dan pendampingan kepada masyarakat sehingga kami selaku tim dapat mentransfer keilmuan kami secara langsung kepada masyarakat. Dan kepada lembaga PKBM Tunas Cendikia semoga kedepan kita bisa berkolaborasi lagi dengan tema kegiatan yang berbeda.

\section{Daftar Pustaka}

Baiquni. (2007). Strategi Pnghidupan di Masa Krisis. Ideas Media.

Chambers, R. (1994). The Origins and Practice of Participatory Rural Appraisal. World Development. 22(7): 953-69.

Dharmawan, A. H. (2007). Sistem penghidupan dan nafkah pedesaan. Jurnal Transdisiplin Sosiologi, Komunikasi, Dan Ekologi Manusia, 1(2), 169-192. https://journal.jpb.ac.id/index.php/sodality/article/viewFile/5932/4609

Gitosaputro, S. (2006). Implementasi Participatory Rural Appraisal (PRA) dalam Pemberdayaan Masyarakat". Komunitas;Pengembangan Masyarakat Islam, 2(1).

Haris, A. (2014). Memahami Pendekatan Pemberdayaan Masyarakat Melalui Pemanfaatan Media. Jupiter, 13(2), 50-62.

Maryani, I., Mustofa, A., \& Septian Emma Dwi, J. (2018). Efektivitas Pendampingan Kelompok Dalam Meningkatkan Motivasi Berwirausaha Peternak Sapi Perah. JPPM (Jurnal Pengabdian Dan Pemberdayaan Masyarakat), $2(1), \quad 7$. https://doi.org/10.30595/jppm.v2i1.2059

Melati, I. S., Margunani, M., Mudrikah, S., \& Pitaloka, L. K. (2020). Upaya Optimalisasi Praktik Digital Marketing untuk Meningkatkan Hasil Penjualan Produk Warga Binaan Lembaga Pemasyarakatan. Panrita Abdi - Jurnal Pengabdian Pada Masyarakat, 4(2), 155. https://doi.org/10.20956/pa.v4i2.7685

Oktaviani, F., \& Rustandi, D. (2018). Implementasi Digital Marketing dalam Membangun Brand Awareness. PRofesi Humas: Jurnal IImiah IImu Hubungan Masyarakat, 3(1), 1. https://doi.org/10.24198/prh.v3i1.15878

Sukamta. (2017). Menghadapi Era Digital.

Sumodiningrat, G. (2000). Visi dan Misi Pembangunan Pertanian Berbasis Pemberdayaan. Idea.

Udin, K., Muta'ali, L., \& Kurniawan, A. (2016). Pola Penghidupan Masyarakat di Daerah Perdesaan pada Strata Rumahtangga yang Berbeda. Majalah Geografi Indonesia, 23(2), 176-188. https://doi.org/10.22146/mgi.13335

Virgilenna, S., \& Anom, I. P. (2018). Strategi Pemasaran Pariwisata Sembalun Kecamatan https://journal.universitasbumigora.ac.id/index.php/ADMA

E-ISSN: 2723-7370 
Sembalun Kabupaten Lombok Timur Nusa Tenggara Barat. Jurnal Destinasi Pariwisata, 6(1), 171. https://doi.org/10.24843/jdepar.2018.v06.i01.p26

Widjajanti, K. (2011). Jurnal Ekonomi Pembangunan Model pemberdayaan masyarakat. 12. Zuraida, I. (1981). Struktur Sosial Ekonomi dan Fertilitas. Fakultas Sosial Politik UGM. 
